\title{
Role of Natural Elements in Provision of Healing Environment: Sustainable Healthcare Building
}

\author{
Seyedehhana Seyedahmadi ${ }^{1}$
}

\begin{abstract}
In order to improve the functional layout of hospital environment and to cope with modern changes, this paper aimed at examining the current architectural conditions in a public hospitals, and clarifying the requirements of spatial planning from the architectural standpoint. Recently, the initiative by the Iranian government to reduce the energy consumption in public buildings including hospitals is seen as the notion for sustainability in the built environment. On the other hand, designing a hospital building is architecturally accepted as a complex task both functionally and psychologically. Therefore, creating a healing environment with functional physical spaces (for example daylight utilization) to achieve sustainable hospital seems relevant and in tandem with sustainability. Many previous studies suggest that adequate and appropriate exposure to natural elements and daylight can provide a positive impact on human health and well-being of patients and medical staff in a hospital environment. This paper reviewed the role of natural elements focusing on daylight utilization as one of the physical aspects in hospital design to create a healing environment, and the effects of physical aspects on patients' outcomes were investigated. Pilot studies on several public hospitals in different cities of Iran, was carried out to investigate the design and utilization of lighting (i.e. artificial and natural light) and its relationship to other environmental factors.
\end{abstract}

Keywords: architecture, environment, hospital, sustainability.

\section{Introduction}

The increasing interest for sustainable or green building in the healthcare system is a clear but paradoxical situation. Does the sustainable or green building treat sickness or promote the condition of health? In hospital design, it is difficult to achieve the ideal link and benefit of sustainability in contributing to the health outcomes of patients. Perhaps, to explain paradox, discussion evolving sustainability in healthcare buildings should embrace the notion of creating a real supportive environment in a hospital (i.e. healing environment) that is physically healthy and psychologically appropriate for everybody. Therefore, it should be the final objective of designing a sustainable hospital. For this, it is important for designers to consider the physical aspects in hospital buildings. The physical aspects (like daylight utilization, window geometry, thermal conditions and others) should be cleverly designed to achieve the balance and the principles of economic, social and ecological sustainability without compromising the functionality of hospital building (Linda, 2004; Aripin, 2007). This paper emphasized two important aspects that lead to sustainability in hospital design: The importance of 
physical aspects to achieve a healing environment and the impact of the physical aspects (including daylight utilization) on health outcomes.

In recent years, different studies regarding the role of nature and natural elements in improvement of quality of architectural space have been done in Iran. Some researchers have paid attention to phenomenological aspects of nature in architectural practice, while others have paid attention to more practical aspects of utilization of natural elements in architecture. On the hand, the situation concerning spatial efficiency in hospitals has changed greatly in Iran. In a public hospital, although there is a growing move towards a shorter hospitalization period, the proportion of critically ill patients is increasing; consequently, the load of providing healing environment has also increased. Furthermore, with the influence of several other factors, the hospital ward's environment is changing drastically. As for the architectural planning of the hospital environment, in Iran, traffic diagram researches of nurses' circulation in wards began in the last decade and are performing actively until now. As a result, a series of design indicators were acquired. Yet, it is unclear whether the application of these guidelines may also be possible for acute wards, especially after reorganization of the medical facilities. Besides, the evolution of digital technology in design and construction industry has provided unprecedented opportunities for improvement of quality in interior spaces (Ghasemi, 2018). On the other hand, the hospital building should provide the patients a sense of safety, comfort, dignity and repose. It should also provide pleasing spaces for patients, families and visitors as well as imbibe the cultural concerns of the community. Kane (2001) emphasized that the design of healthcare setting should welcome the patients family and friends, value human beings over technology and provide flexibility to personalize the care of each patient (Shi \& Singh, 2001; Marfo, 2007).

Besides, hospitals in Iran have been growing in larger numbers and scales. Having accommodated many people with different illnesses, the hospitals are in greater danger and suffer heavier casualties than other buildings regarding the provision of day lighting and comfortable indoor environment. Therefore, daylight utilization assessment regulations for hospital buildings must be more demanding than for other buildings. So far, the Iranian Building Code as well as the ministry of health and medical education have established some limitations on population densities of some divisions in hospital buildings, while such zones as lobbies and emergency rooms are out of consideration regarding the daylight utilization. In addition, the information about people's speeds in hospitals is unavailable. Some related studies are also lacking such background information. For the reasons given above, this paper was intended to investigate daylight utilization and people's comfort in hospitals.

\section{Research Objectives}

The hospitals that are part of the organization because of the sensitivity and importance of the treatment must be agile to survive in today's dynamic and responsive to the needs and demands of their patients (Yusuf et al., 2014) for diagnosis and treatment of patients (Raghupathi and Raghupathi, 2014) and improve their service quality (Popowich, 2005; Abdi et. al., 2018). 
In a hospital environment, there are still many unknown issues regarding the actual situation, regarding the hospitalized patients and the environmental conditions, in relation to the layout of the floor plan. Against this background and based on the priority for environmental conditions and treatment in hospitals, this paper aimed to provide the date required for improvement of functional layout of hospitals to cope with modern changes derived from the architectural standpoint, by examining the current condition of daylight utilization in a public hospital, evaluating the current hospital planning, and clarifying the spatial requirements of hospital planning, based on the results of observation studies, a questionnaire survey and an interview.

\section{Methodology}

An extraction and assembly of the body of knowledge regarding the physical characteristics of healing environment in hospital design is reviewed in this paper. It is intended to identify potential research domains on the physical aspects of healing environment in hospital design particularly regarding the daylight utilization. The methodology and process for the development of this study can be divided into four stages as follows.

In the first stage (follow-up observation survey), behavior of medical staff were observed in several public hospitals in 2017. An observer followed each person; and all of her/his trips, places visited, time and work done were recorded chronologically. A second observation study (fixed-point observation survey) was carried out during the day duty on the same day of the following week. For this latter study, five observers were positioned in designated locations and recorded the time of entering and exiting of each person in medical staff from each room. A questionnaire completed by medical staff, as the user, was undertaken to evaluate a hospital physical quality in 2017. An interview was undertaken in 2017 with head managers to get information about staffing, work responsibilities, the features of the patients, procedures of nursing activities, and the problems.

Then, a comparative analysis was carried out in order to explore changes in the results of this observation investigation compared with the results of previous studies. The compared items are as follows, and were widely analyzed in past research.

a) Spatial Quality of Public Spaces (SQPS), an index for the self-reported quality of public spaces in hospital.

b) Spatial Quality of Patients' Rooms (SQPR), an index to evaluate the selfreported quality of space in room.

Finally, physical, management, patient and nurse factors of spatial layout of hospital that affect environmental conditions were discussed based on the result of observation investigation and a questionnaire, in order to clarify the impact of these factors on comfort of staff and patients.

\section{Findings}

The data obtained by this survey and collected from previous studies concerning this subject are shown in Table 1., and were used as analytical data and the basis of un- 
correlational tests in order to clarify the impact of the 6 physical factors influencing the spatial quality (size of openings, ratio of openings to room area, floor area of room per bed, number of windows, number of patients, ratio of patient attention level: level $\mathrm{A}$ and level B patients) on the SQPS on day duty, with a significance probability of $a=5 \%$ null hypothesis (the SQPS and the factors are assumed to be unrelated). The results are shown in Table 2.

Table 1: Impact of Physical Factors on Spatial Quality Based on Previous Studies.

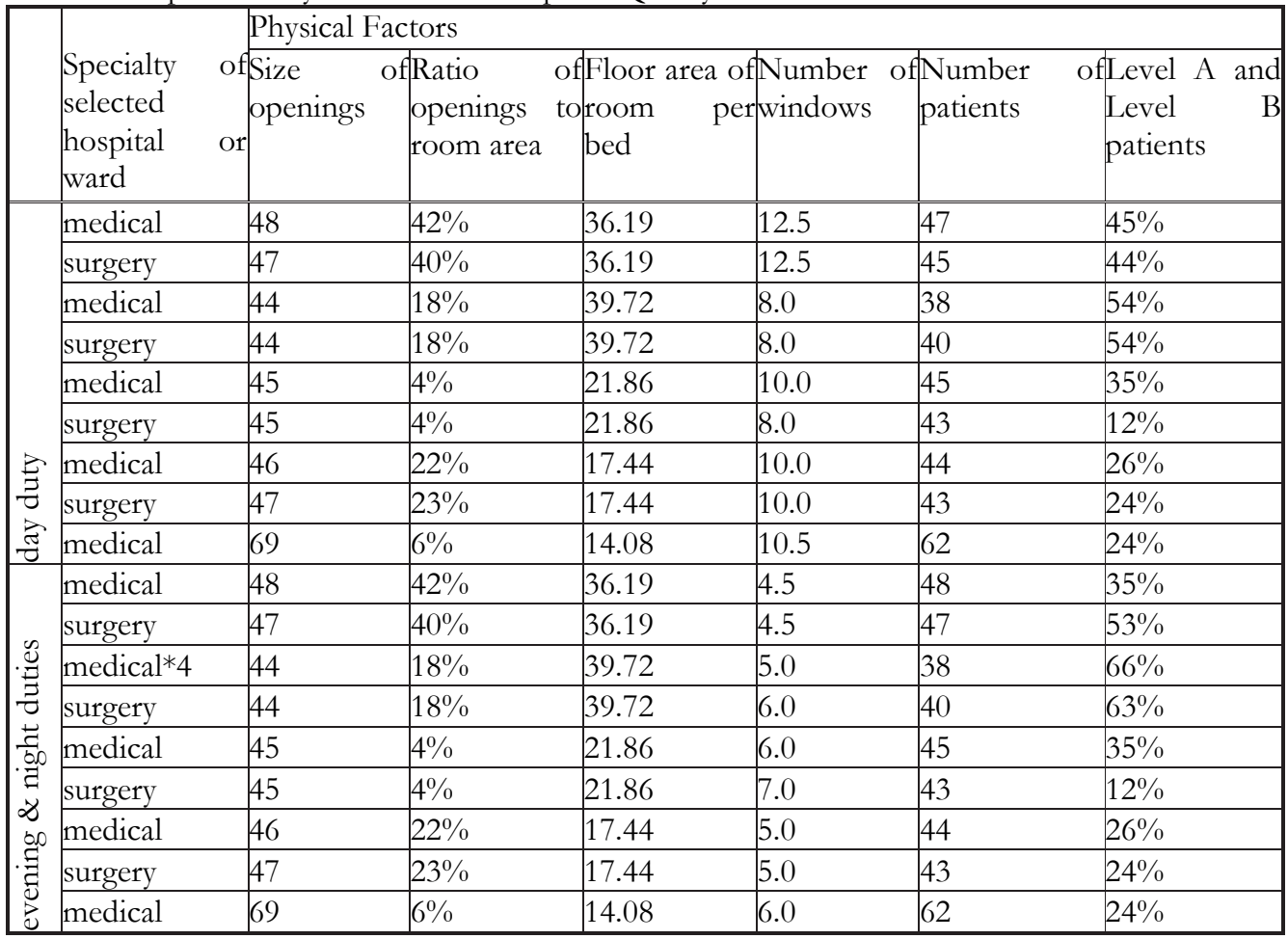

Table 2: The Results of the Un-correlational Test against the Impact of Six physical Factors on the SQPS on Day Duty

\begin{tabular}{|l|l|l|l|l|}
\hline Factors & $\begin{array}{l}\text { Number of } \\
\text { samples } \\
\text { correlation }\end{array}$ & $\begin{array}{l}\text { Significance } \\
\text { probability }\end{array}$ & udgment \\
\hline Size of openings & 9 & -0.006 & 0.494 & Uncorrelated \\
\hline $\begin{array}{l}\text { Ratio of opening to } \\
\text { room area }\end{array}$ & 9.656 & 0.027 & Correlated \\
\hline $\begin{array}{l}\text { Floor area of room per } \\
\text { bed }\end{array}$ & 0.097 & 0.402 & Uncorrelated \\
\hline $\begin{array}{l}\text { Number of windows } \\
\text { Number of patients }\end{array}$ & 9 & 0.498 & 0.086 & Uncorrelated \\
\hline $\begin{array}{l}\text { Level A and level B } \\
\text { patients }\end{array}$ & -0.042 & 0.457 & Uncorrelated \\
\hline
\end{tabular}


Firstly, the factor of size of openings is discussed. Because the significance probability is $0.494>$ significant level $a=5 \%$, the assumption is reasonable. That is, the amount of SQPS on day duty is not related to the size of openings. It is also similar for other factors such as the floor area of room per bed, number of windows, number of patients, and level A and level B patients which seems to be unrelated. Next, the factor of the ratio of opening to room area was investigated. Because the significance probability of $0.027<$ significant level $a=5 \%$, it refutes the hypothesis. That is, the ratio of opening to room area is correlated to the amount of the SQPS by nurses on day duty. On day duty, the number of SQPS is increasing with the ratio of opening to room area. The results of the un-correlational test on the SQPS and the amount of SQPR for evening and night duties are shown in Tables 3. and 4. It appears that both the SQPS and the amount of the SQPR for evening and night duties are decreasing, while the RABP is increasing. It shows that the workload of nurses is approaching the limit on evening and night duties.

Table 3: The Result of the Un-correlational Test against the Impact of Six Physical Factors on the SQPS on the Evening and Night Duties

\begin{tabular}{|l|l|l|l|l|}
\hline Factor & $\begin{array}{l}\text { Number } \\
\text { samples }\end{array}$ & $\begin{array}{l}\text { Correlation } \\
\text { Coefficient }\end{array}$ & $\begin{array}{l}\text { Significance } \\
\text { probability }\end{array}$ & udgment \\
\hline Size of openings & 9 & -0.471 & 0.1 & Uncorrelated \\
\hline $\begin{array}{l}\text { Ratio of opening to room } \\
\text { area }\end{array}$ & -0.23 & 0.276 & Uncorrelated \\
\hline $\begin{array}{l}\text { Floor area of room per } \\
\text { bed }\end{array}$ & -0.394 & 0.147 & Uncorrelated \\
\hline Number of windows & 9 & 0.375 & 0.16 & Uncorrelated \\
\hline Number of patients & 9 & -0.371 & 0.162 & Uncorrelated \\
\hline $\begin{array}{l}\text { Level A and level B } \\
\text { patients }\end{array}$ & -0.586 & 0.049 & Correlated \\
\hline
\end{tabular}

Table 4: The Results of the Un-correlational test against the Impact of Six Physical Factors on the SQPR on Evening and Night Duties

\begin{tabular}{|l|l|l|l|l|}
\hline Factors & $\begin{array}{l}\text { Number of } \\
\text { samples }\end{array}$ & Correlation coefficient & $\begin{array}{l}\text { Significance } \\
\text { probability }\end{array}$ & udgment \\
\hline Size of openings & 9 & -0.016 & 0.484 & Uncorrelated \\
\hline $\begin{array}{l}\text { Ratio of opening to room } \\
\text { area }\end{array}$ & -0.741 & 0.011 & Correlated \\
\hline $\begin{array}{l}\text { Floor area of room per } \\
\text { bed }\end{array}$ & -0.507 & 0.082 & Uncorrelated \\
\hline $\begin{array}{l}\text { Number of windows } \\
\text { Number of patients }\end{array}$ & 9 & 0.8 & 0.005 & Correlated \\
\hline $\begin{array}{l}\text { Level A and level B } \\
\text { patients }\end{array}$ & -0.042 & 0.457 & Uncorrelated \\
\hline
\end{tabular}

Data concerning single-bed patient rooms are extracted and analyzed with regards to the Patient Attention Level (PAL). It is observed that the SQPR and the SQPS differ greatly according to the PAL. The two factors were observed to be high for level A patients, and weak for level B patients. 
Furthermore, it is observed that level B and level C patients in the target hospital received less attention as compared to the other units, whereas in the same hospital, the level A patients seem to be receiving more attention.

\section{Suggestions for Spatial Quality Improvement}

Improvement of the environment in a hospital must be discussed from both the management level and the point of view of the physical environment based on the architectural aspects. The proposals for spatial planning of hospitals from the standpoint of architects are concluded as follows.

1) Sufficient attention must be paid to the different needs of treatment and healing depending on the medical conditions of the patients when spatially planning a hospital. In the early stages of planning, firstly, patients' information including the percentage of critically ill patients must be analyzed carefully. The composition of the different wards must be discussed considering staffing and the efficiency of operation, along with the highest level of medical care. The zoning corresponding to the ratio of critically ill patients also needs to be fully considered when arranging the layout of medical units.

2) The patients' rooms must be arranged in a situation where the best utilization of natural elements including daylight become possible. Special attention must be paid to the spatial planning in order to provide the necessary number of windows.

3) Efforts must be made in order to improve the spatial recognition in hospitals.

\section{Discussion}

The main changes in floor plans include the dispersed location of toilets, the increase in the floor area of the rooms, the length of the corridor and the ratio of openings to room area. The standard floor area per bed is $38 \mathrm{~m} 2$, and is $1.7 \sim 3.5$ times that of the area found in previous studies $(14 \sim 22 \mathrm{~m} 2)$. The expansion of the area of the hospital units ensured sufficient working space and allowed work to be carried out easily. In contrast, both the distance and the time of the nurses' circulation became longer. On the other hand with the area and the ratio of openings to room area increasing, new problems emerged, thus supervision became more difficult and it became impossible for nurses to supervise all the activities. For example, if one staff is in one of the corridors, he/she cannot grasp the situation of other members of staff in other corridors. Otherwise, the supervision of the private rooms by means of senses such as sight or noise made by patients falling, especially when these are located far away from station became difficult. The introduction of monitors and sensors for ambulation is increasing. But the alarms located too far away are also out of audible range. Additionally, as the floor area of stations becomes larger, there are also many passages being introduced, thus where the sound of the alarm is coming from is at times unclear.

With the expansion of the area, the number of corridors is also increasing. The spatial intelligibleness is becoming scarcer. Moreover, in order to secure privacy, the room number and the name of patients are displayed on a panel when touched. From the architectural viewpoint, a dispersed distribution of toilets has both merits and demerits. Waste and removal of drains can be performed easily in the toilets inside the private 
rooms. But, in order to record all the amount of excretion and to take urine samples, it becomes necessary to go to each and every private room. In previous studies, patients visited the centralized toilets frequently and had to walk through the corridors. But now patients can do everything in their own rooms. Consequently, the contact between staff and patients has decreased.

\section{Conclusions}

Achieving sustainable hospital design through appropriate physical aspects is not an impossible or hard task. The growing research evidence and the pilot studies conducted in the Iranian public hospitals provide unequivocal direction to suggest that the physical aspects have a significant role in creating a healing environment. In the context of healthcare facilities and buildings, the measurable health outcomes related to patients in a healing environment are indirectly the result of appropriate planning and design approach to physical aspects. Thus, the role of natural elements like daylight utilization as one of the physical aspects having a significant impact on the well-being of both the staff and the patients, as well as the visitors. It is without doubt that well designed buildings with access to natural elements and enough daylight utilization will obviate the need for utilization of artificial lighting. The effort to reduce dependency on mechanical systems and artificial lighting would directly contribute to the reduction of energy consumption of hospital buildings, subsequently assisting the achievement of sustainability.

Creating a healing environment with appropriate design of physical aspects with enough link to natural elements (like daylight utilization) in hospital buildings in Iran should be rigorously pursued. Professionals in the healthcare services should also be inspired with the availability of natural environment (including daylight utilization and provision of natural view) in the Iranian climate without sacrificing clinical functionality and design visions. Planners and designers must accept the fact that the subject of healing is a multidisciplinary subject requiring diverse methods. Thus, a coordinated effort by healthcare professionals and others (architects, engineers, psychologist and lighting specialist) will be able to achieve a better hospital building not only for healing environment that is physically healthy and psychologically appropriate but also for implementation of sustainable design.

The effort to have sustainable or green design for public hospitals in Iran through improved procurement system can be a valuable commendable starting point. However, stringent requirements on the physical aspects to meet environmental requirements should be explicitly stated in the design programs of hospital planning and developments. These requirements must conform to related standards used by healthcare designers and validated by the healthcare providers.

\section{References}

Abdi, M. et al. (2018). Agile design of public hospitals in Iran, Bali Medical Journal (Bali Med J), 7(2): $285-289$. Aripin, S. (2006), 'Healing architecture': a study on the physical aspects of healing environment in hospital design. Paper presented at the 40th Annual Conference of the Architectural Science Association (ANZAScA), Adelaide, Australia, 22 - 25 November 2006, pp. 342 - 9. 
Aripin, S. (2007). Healing Architecture: Daylight in Hospital Design. Conference on Sustainable Building South East Asia, 5-7 November, Malaysia.

Ghasemi, E. (2018). The evolving role of digital technology in architectural design. Online Journal of Engineering Sciences and Technologies, 1(3), 1-6.

Kane (2001). Health care Manager. Washington, DC: Federation of Nurses and Health Professionals.

Popowich, F. (2005). Using text mining and natural language processing for health care claims processing. ACM SIGKDD Explorations Newsletter.7(1):59-66.

Raghupathi, W., Raghupathi, V. (2014). Big data analytics in healthcare: promise and potential. Health Information Science and Systems, 2(1):3.

Shi, L., \& Singh, D. (2001). Delivering health care in America: A systems approach (2nd ed). Gaithersburg, MD: Aspen Publishers

Yusuf, Y.Y., Gunasekaran, A., Musa, A., Dauda, M., El-Berishy, N.M., Cang, S. (2014). A relational study of supply chain agility, competitiveness and business performance in the oil and gas industry. International Journal of Production Economics, 147:531-43. 